University of Nebraska - Lincoln

DigitalCommons@University of Nebraska - Lincoln

January 1997

\title{
High resolution imaging of thin-film recording heads by superparamagnetic magnetic force microscopy tips
}

Sy_Hwang Liou

University of Nebraska-Lincoln, sliou@unl.edu

S.S. Malhotra

University of Nebraska - Lincoln

John Moreland

National Institute of Standards and Technology, Boulder, Colorado

P.F. Hopkins

Quantum Peripherals of Colorado, Louisville, Colorado

Follow this and additional works at: https://digitalcommons.unl.edu/physicsliou

Part of the Physics Commons

Liou, Sy_Hwang; Malhotra, S.S.; Moreland, John; and Hopkins, P.F., "High resolution imaging of thin-film recording heads by superparamagnetic magnetic force microscopy tips" (1997). Si-Hwang Liou Publications. 63.

https://digitalcommons.unl.edu/physicsliou/63

This Article is brought to you for free and open access by the Research Papers in Physics and Astronomy at DigitalCommons@University of Nebraska - Lincoln. It has been accepted for inclusion in Si-Hwang Liou Publications by an authorized administrator of DigitalCommons@University of Nebraska - Lincoln. 


\title{
High resolution imaging of thin-film recording heads by superparamagnetic magnetic force microscopy tips
}

\author{
S. H. Liou ${ }^{\text {a) }}$ and S. S. Malhotra \\ Department of Physics and Astronomy, and Center for Materials Research and Analysis, \\ University of Nebraska, Lincoln, Nebraska 68588-0111 \\ John Moreland \\ National Institute of Standards and Technology, Boulder, Colorado 80303 \\ P. F. Hopkins \\ Quantum Peripherals of Colorado, Louisville, Colorado 80028-8188
}

(Received 29 April 1996; accepted for publication 4 November 1996)

\begin{abstract}
We have used superparamagnetic magnetic force microscopy (MFM) tips to obtain high spatial resolution MFM images of recording heads. Profiles of the magnetic field gradient above a thin-film recording head under $3 \mathrm{~mA}$ bias current to the head and various tip-head distance conditions are presented. At a low tip-head distance, the gap width, gap location, and gap-field structure can be well resolved in these MFM images. Superparamagnetic tips show promise for the magnetic imaging of recording heads with gap widths below $200 \mathrm{~nm}$. (C) 1997 American Institute of Physics. [S0003-6951(97)01701-4]
\end{abstract}

Magnetic force microscopy (MFM) has been used to study the field profile of thin-film recording heads. ${ }^{1-13}$ MFM applications in the design and development disk drive components have expanded rapidly over the last few years because of the need to explore nanometer scale phenomena that limit recording density. In this letter, we report a method to improve resolution in the measurement of gap-field profiles of thin-film recording heads. We have been able to determine relevant details of the gap-field profiles and precisely determine the gap position.

It is very difficult to characterize and evaluate the magnetic response of thin-film heads before they have been incorporated into a disk drive. Presently, most studies of recording head response are based on direct recording performance. The direct determination of the head-field profile is very useful when comparing the performance of the recording head with design models. Quantifying the spatial variation of head fields and field gradients provides a useful feedback to the design goals, and is critical for the development of new heads. It is not easy to explain the gap-field structure from MFM images of recording heads, because (1) the field profile is not well resolved, (2) the magnetic hysteresis in the MFM tips causes history-dependent interactions between the tip and the sample, and (3) the "semihard" magnetic nature of the MFM tip coatings produces images that are difficult to use in estimating field profiles in the gap, due to the huge magnetic flux densities in proximity to the gap. As recording densities increase, recording gaps in future heads may be even smaller than the currently typical values of 200-500 nm. ${ }^{14}$ Improvements in MFM techniques are clearly needed to keep pace with industrial developments.

The advantage of using superparamagnetic tips in the imaging of recording heads was demonstrated recently. ${ }^{13} \mathrm{In}$ comparison to the MFM images taken using $\mathrm{Co}_{85} \mathrm{Cr}_{15}$ coated tips, the MFM images using superparamagnetic tips shows

${ }^{a)}$ Present address: National Institute of Standard and Technology, Boulder, CO 80303. Electronic mail: sliou@unlinfo.unl.edu reduced tip hysteresis effects and clearly delineate the gapfield profiles from the pole pieces.

The tips used in this experiment were commercial silicon micromachined cantilevers coated with superparamagnetic $\mathrm{Fe}_{70}\left(\mathrm{SiO}_{2}\right)_{30}$ films. The cantilevers have spring constants of $1-5 \mathrm{~N} / \mathrm{m}$, resonant frequencies of $70-89 \mathrm{kHz}$, and quality factors of about 200 in air. Details of the film preparation and its magnetic properties can be found in previous publications. ${ }^{15-18}$ The samples investigated were inductive thin-film recording heads typical of those currently found in hard-disk drives. The gap width of these thin-film recording heads is about $200 \mathrm{~nm}$. The recording heads were driven by a dc current in the range of 2 to $10 \mathrm{~mA}$. The topographic and magnetic images were taken simultaneously permitting direct correlation of magnetic profile to the topography of the pole pieces. The topographic data were taken by an atomic force microscope (AFM) in intermittent contact and the magnetic data (MFM image) were recorded with the tip at various fixed distances from the air bearing surface (ABS) of the thin-film recording head. ${ }^{19-22}$ In this method, the force gradient between the sample and the sensing tip was measured by the frequency shift of the cantilever.

The best MFM spatial resolution occurred while the tips were scanned at nearly zero distance above the ABS. The actual distance above the ABS is about half of the rms amplitude of the cantilever plus the scan height. The distance between the center of the vibrating cantilever and the surface of the sample was fixed when the MFM image was recorded. As the vibration amplitude goes down, the tip moves away from the surface. One of the methods to achieve nearly zero distance above the ABS is to use a low scan height and gradually reduce the vibration amplitude until there is no topography interaction between the cantilever and the sample during the recording of the magnetic signal. The lowest distance above ABS achieved in this work was about $15 \mathrm{~nm}$ which is half of the rms amplitude of the cantilever. The vibrating amplitude used for acquisition of MFM images (about $8 \mathrm{~nm}$ ) was about 1/4 of the amplitude used for acqui- 


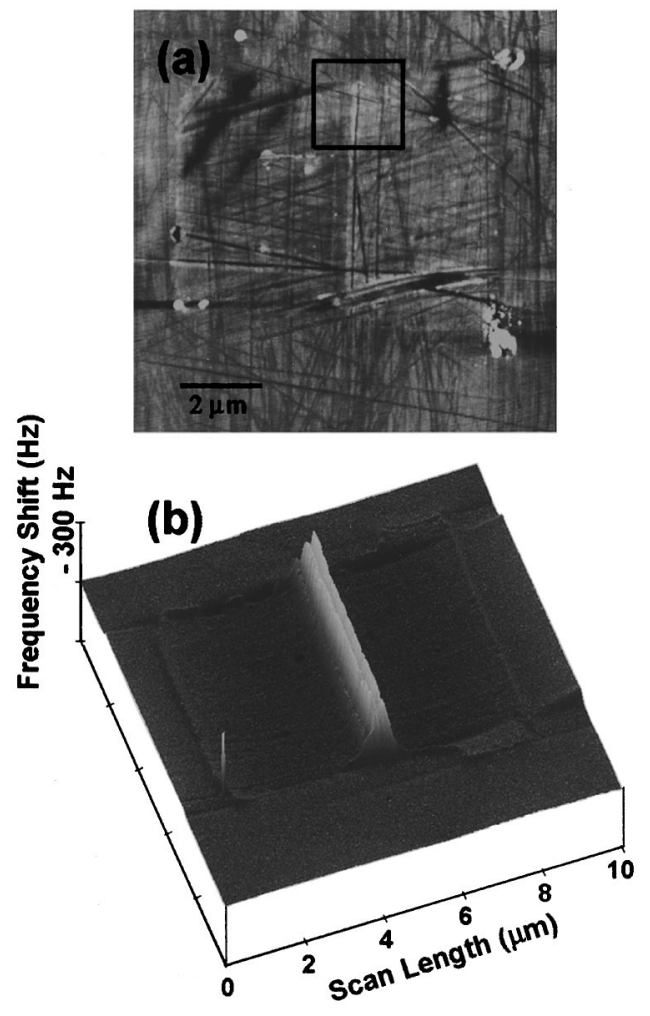

FIG. 1. $10 \mu \mathrm{m} \times 10 \mu \mathrm{m}$ images of a thin-film recording head, by using an $80 \mathrm{~nm} \mathrm{Fe}{ }_{70}\left(\mathrm{SiO}_{2}\right)_{30}$ superparamagnetic tip. (a) AFM image, (b) corresponding MFM image with $15 \mathrm{~nm}$ tip-head spacing, and $3 \mathrm{~mA}$ current bias to the head. The color-contrast scales for (a) and (b) are $20 \mathrm{~nm}$ and $300 \mathrm{~Hz}$ respectively. In (b), the light color represents attractive force (i.e., a reduction of the frequency).

sition of topographic images. The reduction of the cantilever vibration amplitude does not affect the magnitude of the frequency shift. We observed only a decrease of the signal to noise $(\mathrm{S} / \mathrm{N})$ ratio. It has been shown that the signal is proportional to the thickness of magnetic coating of MFM tips. ${ }^{23}$ In this report, we show only the results obtained using a 80 $\mathrm{nm} \mathrm{Fe}_{70}\left(\mathrm{SiO}_{2}\right)_{30}$ tip coating which is twice the thickness used in the previous work. ${ }^{13}$ The results obtained from using the $\mathrm{Fe}_{70}\left(\mathrm{SiO}_{2}\right)_{30}$ tips with 40-nm-thick coatings are similar and have about half the frequency shift of the $80 \mathrm{~nm}$ tips.

Figure 1 shows $10 \mu \mathrm{m} \times 10 \mu \mathrm{m}$ images of a thin-film recording head using a $\mathrm{Fe}_{70}\left(\mathrm{SiO}_{2}\right)_{30}$ superparamagnetic MFM tip with a coating thickness of $80 \mathrm{~nm}$. Figure 1(a) is a topographical image of the recording region taken by the AFM. The cantilever was vibrated at a resonance frequency of $77.2182 \mathrm{kHz}$ with about $30 \mathrm{~nm} \mathrm{rms}$ amplitude. It shows a typical thin-film recording head with two pole pieces that are approximately $4 \mu \mathrm{m} \times 6 \mu \mathrm{m}$ each as measured by the AFM. The gap is visible between the pole pieces, as are polishing marks that happen when the pole pieces are lapped. Figure 1(b) is the corresponding MFM image of the same region in Fig. 1(a). This image was taken with a bias current of $3 \mathrm{~mA}$ to the head, and tip-head distance of about $15 \mathrm{~nm}$. The tip is not touching the sample, since the topographic features do not appear in the magnetic image. Fringing fields around the head poles are clearly visible. Unlike images taken with other types of magnetic tips and tip coatings, ${ }^{1-12}$ the images taken with a superparamagnetic tip show only a small fre-
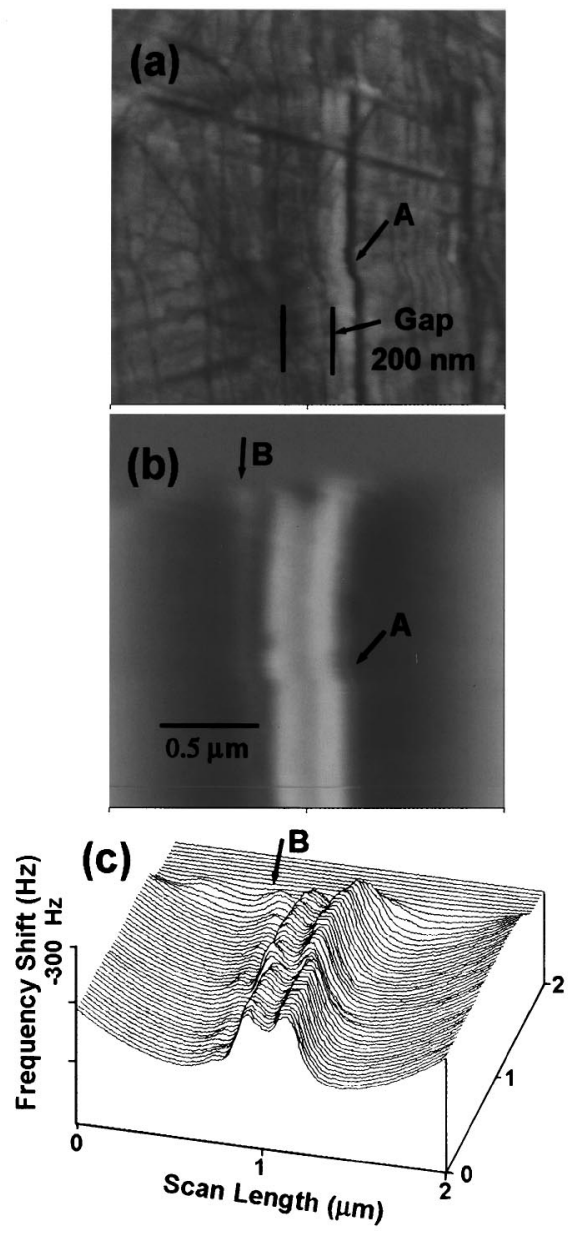

FIG. 2. $2 \mu \mathrm{m} \times 2 \mu \mathrm{m}$ images of a thin-film recording head, by using an 80 $\mathrm{nm} \mathrm{Fe} 70\left(\mathrm{SiO}_{2}\right)_{30}$ superparamagnetic tip. (a) AFM image corresponds to the boxed area that is shown in Fig. 1(a); (b) corresponding MFM image with a $15 \mathrm{~nm}$ tip-head spacing, and $3 \mathrm{~mA}$ current bias to the head; (c) the line plot of the MFM image (b). The color-contrast scales for (a) and (b) are $20 \mathrm{~nm}$ and $300 \mathrm{~Hz}$, respectively. In (b), the light color represents attractive force. In (c), the peak corresponds to the reduction of the frequency.

quency shift above pole pieces and response to the field gradient. A principle feature of superparamagnetism is the lack of hysteresis; that is, it has zero remanance and magnetic coercivity. In contrast to the assumed fixed magnetic moment, $\mathbf{m}$, of ferromagnetic coated tips, $\mathbf{m}$ for superparamagnetic tips depends on the applied magnetic field. The magnetization is always along the field direction, so the net force is always attractive. Because of the field dependence of the magnetization of the tip, the interaction is very sensitive to the strength of the magnetic field as well as the field gradient.

As shown in Fig. 1(b), the gap position and the gap structure are clearly observed. There is a clear double peak, which is expected due to the strong field gradient near the pole pieces. The field-gradient profile is asymmetric, with an additional peak at the left side of the double peak. This suggests that there is a small magnetic flux leakage that may be due to the insufficient magnetic coupling at the interface between the gap layer and the left pole piece.

Figure $2(\mathrm{a})$ is a $2 \mu \mathrm{m} \times 2 \mu \mathrm{m}$ topographic image corresponding to the box shown in Fig. 1(a). Figure 2(b) is an MFM image corresponding to the topography in Figs. 2(a) 


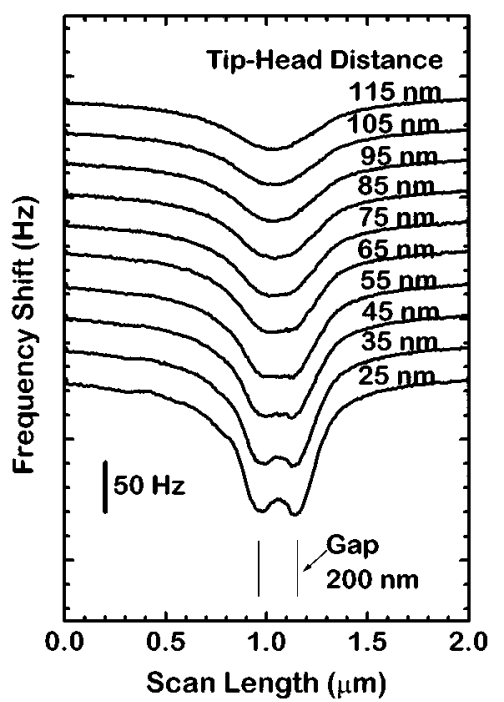

FIG. 3. 2- $\mu \mathrm{m}$ traces taken horizontally across the gap of the thin film recording head, with a bias current to the head $3 \mathrm{~mA}$ and at different tip-head distances. The measured frequency shift is proportional to the force gradient on the MFM tip.

and 2(c) is the contour plot of the image Fig. 2(b). The width of the gap measured by magnetic imaging is about $200 \pm 15$ $\mathrm{nm}$, which is very close to that estimated from the topographic imaging [as marked in Fig. 2(a)] and the specification from the manufacturer. The position of the gap, as indicated from the MFM image, also corresponds to that of the topographic image. The gap is not straight [marked as "A" in Figs. 2(a) and 2(b)]. A small distortion can be seen in the region close to the end of the gap. The distortion is possibly caused by the manufacturing process. In addition to the distortion, the magnetic profile shows asymmetry and an additional peak in the field profile which is more pronounced near the end of the gap [indicated by " $\mathrm{B}$ ', in Figs. 2(b) and $2(\mathrm{c})]$. The asymmetry in the field-gradient profile, also shown in the Fig. 1(b), does not depend on the direction of the bias current and occurs only near the left pole. As suggested earlier, this magnetic flux leakage is possibly caused by different interfaces between the two pole pieces and the gap layer.

Figure 3 shows the $2 \mu \mathrm{m}$ line traces taken horizontally across the gap of the thin film recording head, with a fixed head current bias of $3 \mathrm{~mA}$, and at different tip-head distances. The traces are essentially flat above the pole-piece region and show a large frequency shift in the gap region. The shape of the field-gradient profile of the recording head changes with tip-sample distance. Below a tip-sample distance of $35 \mathrm{~nm}$, which is much smaller than the gap width, two peaks were observed. As expected from Karlqvist's formula for thin-film head fields, ${ }^{24}$ there are two peaks at a scan height much smaller than the gap width. When the scan height increases, the double-peak feature smears out. It is also consistent to our earlier results, ${ }^{13}$ where we observed only a single peak, and the estimated gap width was about 2-3 times higher than the actual gap width. This was due to the large tip-sample distance $(\sim 100 \mathrm{~nm})$ used in the previous experiments. As shown in Fig. 3, the gap width and position are more accurately measured because of the reduced tiphead distance. The shape of the field-gradient profile did not change when the direction of the current was reversed (data not shown). This also means that the force between the tip and the sample is always attractive and does not depend on the direction of the magnetic field. Near the gap region, the frequency shift of the cantilever increases with increasing bias current and saturates at a current of about $4 \mathrm{~mA}$, in agreement with the head manufacturer's specifications.

In summary, we have shown a method using a superparamagnetic tip coating that allows us to obtain highresolution MFM images of thin-film recording heads. The gap width and the gap-field structure are well resolved. Furthermore, we should be able to image a recording head with a gap width well below $200 \mathrm{~nm}$. The implication of distortions of magnetic field-gradient profiles in recording heads should be interesting for further study of correlation to recording performance.

We thank P. Rice and R. E. Thomson for many interesting discussions. The work at the University of Nebraska was supported by NSF Grant No. QSR-9255225.

${ }^{1}$ Y. Martin and H. K. Wickramasinghe, Appl. Phys. Lett. 50, 1455 (1987). ${ }^{2}$ C. Schönenberger, S. F. Alvarado, S. E. Lambert, and I. L. Sanders, J. Appl. Phys. 67, 7278 (1990).

${ }^{3}$ C. Schönenberger and S. F. Alvarado, Z. Phys. B 80, 373 (1990).

${ }^{4}$ K. Wago, K. Sueoka, and F. Sai, IEEE Trans. Magn. MAG-27, 5178 (1991).

${ }^{5}$ K. Sueoka, K. Okuda, M. Matsubara, and F. Sai, J. Vac. Sci. Technol. B 9, 1313 (1991).

${ }^{6}$ O. Watanuki, F. Sai, and K. Sueoka, Ultramicroscopy 42-44, 315 (1992).

${ }^{7}$ K. Sueoka, K. Wago, and F. Sai, IEEE Trans. Magn. MAG-28, 2307 (1992)

${ }^{8}$ S. Takayama, K. Sueoka, H. Setoh, R. Schafer, B. E. Argyle, and Trouilloud, IEEE Trans. Magn. MAG-28, 2647 (1992).

${ }^{9}$ G. Persch and H. Strecker, Ultramicroscopy 42-44, 1269 (1992).

${ }^{10}$ K. Sueoka, F. Sai, K. Parker, and Arnoldussen, J. Vac. Sci. Technol. B 12, 1618 (1994).

${ }^{11}$ P. Rice, B. Hallett, and J. Moreland, IEEE Trans. Magn. 30, 4248 (1994).

${ }^{12}$ P. Rice, J. Moreland, and A. Wadas, J. Appl. Phys. 75, 6878 (1994).

${ }^{13}$ P. F. Hopkins, J. Moreland, S. S. Malhorta, and S. H. Liou, J. Appl. Phys. 79, 6448 (1996)

${ }^{14}$ S. Gupta, A. Tsoukatos, G. Chaput, and L. E. Tagliani, Data Storage July/August, 43 (1995).

${ }^{15}$ G. Xiao, S. H. Liou, A. Levy, J. N. Taylor, and C. L. Chien, Phys. Rev. B 34, 7573 (1986).

${ }^{16}$ S. H. Liou and C. L. Chien, Appl. Phys. Lett. 52, 512 (1991).

${ }^{17}$ Y. Kanai and S. H. Charap, J. Appl. Phys. 69, 4478 (1991).

${ }^{18}$ S. S. Malhorta, Y. Liu, J. X. Shen, S. H. Liou, and D. J. Sellmyer, J. Appl. Phys. 76, 6304 (1994).

${ }^{19}$ T. R. Albrecht, P. Grütter, D. Horne, and D. Rugar, J. Appl. Phys. 69, 668 (1991).

${ }^{20}$ Q. Zhong, D. Inniss, K. Kjoller, and V. B. Elings, Surf. Sci. Lett. 290, L688 (1993).

${ }^{21}$ K. Babcock, Data Storage 1, 43 (1994).

${ }^{22}$ P. Grütter, H. J. Mamin, and D. Rugar, in Scanning Probe Microscopy II (Springer, New York, 1991).

${ }^{23}$ K. Babcock and V. Elings, IEEE Trans. Magn. 30, 4503 (1994).

${ }^{24}$ O. Karlqvist, Trans. Roy. Inst. Technol. Stockholm 86, 3 (1954). 